\title{
The relevance of metal organic frameworks (MOFs) in inorganic materials chemistry
}

\author{
SRINIVASAN NATARAJAN*, PARTHA MAHATA and DEBAJIT SARMA \\ Framework solids Laboratory, Solid State and Structural Chemistry Unit, Indian Institute of Science, \\ Bangalore 560 012, India \\ e-mail: snatarajan@sscu.iisc.ernet.in
}

\begin{abstract}
The metal organic frameworks (MOFs) have evolved to be an important family and a corner stone for research in the area of inorganic chemistry. The progress made since 2000 has attracted researchers from other disciplines to actively engage themselves in this area. This cooperative synergy of different scientific believes have provided important edge and spread to the chemistry of metal-organic frameworks. The ease of synthesis coupled with the observation of properties in the areas of catalysis, sorption, separation, luminescence, bioactivity, magnetism, etc., are a proof of this synergism. In this article, we present the recent developments in this area.
\end{abstract}

Keywords. Metal-organic framework; luminescence; catalysis; adsorption.

\section{Introduction}

Compounds based on metal organic frameworks (MOF) has evolved to be an important area of research in materials chemistry. ${ }^{1}$ Multidimensional infinite structures of MOF have been prepared by a careful combination of the geometrical preferences of the metal ion and the functionalities of the organic ligands. ${ }^{2}$ The well-established principles of supramolecular chemistry have been quite beneficial in the assembly of MOFs through rational design. ${ }^{3}$ The assemblage of the many components in a MOF structure could create stereochemical issues due to the specific coordination requirements of the metal ion and the bulkiness of the participating organic ligand. Some of the problems have been vitiated, in select cases, by using metals that require larger coordinations such as the rare earths. In spite of these constraints, the research on MOFs is growing exponentially; the ample proof of which can be found in many reviews and highlighted articles available in the literature. ${ }^{1,3}$

From the structural point of view, except for select examples of MOFs stabilized in highly ordered structures, ${ }^{4}$ many MOFs have complex connectivities. This has propelled researchers to visualize them as topologies based on well-known networks. ${ }^{5}$ Topological descriptions have been gainfully employed for the understanding of complex structures of aluminosilicate zeolites and related materials. Generally, in this approach, the complex structures are simplified by con-

*For correspondence sidering connectivities that define the two-dimensional layers. The layers, in turn, can be described as network topologies derived upon hexagons, squares, triangles, etc. This approach, indeed, is beneficial for describing and understanding many MOF structures. ${ }^{5}$

The continuing interests in MOFs are driven by the fact that they are easily prepared and have structures comparable to the aluminosilicate zeolites. In addition, the organic moiety can have (i) chiral centers and (ii) impart chirality to the MOF structures and (iii) provide functionalities to the framework. The structural advantages are important in realizing many properties in MOFs, some of which are potential. The MOF possess excellent sorption capabilities, which are due to the open nature of the structures. The presence of coordinatively unsaturated metal centers in MOF structures can also provide ideal reaction sites (catalyst) for many important reactions. Interesting optical behaviour can be observed in MOFs as the organic moiety can be easily excited through optical means, which would transfer the energy to the metal centers. This is especially true for compounds prepared using the lanthanide ions. Thus, MOFs not only have interesting structures, but also exhibit properties that can be modified to suit the requirements. This article highlights some of the recent developments in this area.

\section{Synthesis}

Synthesis is a crucial component of any experimental research. There have been considerable variations 
attempted in the preparation of metal-organic frameworks. Here, few select methods would be highlighted. Majority of the MOFs were synthesized employing hydro/solvothermal routes. As mentioned earlier, the principles of self-assembly have been extensively used for the preparation of MOFs. Of the many variables in the synthesis, the role of time and temperature is important. The role of temperature has been studied by many researchers. ${ }^{6}$ It appears that the increase in the reaction temperature gives rise to compounds possessing $-\mathrm{M}-\mathrm{O}-\mathrm{M}$ - linkages and $-\mathrm{M}-\mathrm{O}-\mathrm{M}-$ clusters due to an entropy driven dehydration process. ${ }^{6}$ These observations suggest that the formation of MOFs as a function of temperature could be thermodynamically controlled. The formation of traditional framework compounds such as the aluminosilicates and the aluminophosphates are generally kinetically controlled. The variations of reaction time as a function of temperature have also been investigated. ${ }^{6}$ The studies of this nature, though not many, clearly bring out the subtle competition between the kinetic and the thermodynamic parameters during the formation of MOFs. From the available data, it is clear that further investigations are necessary to understand the relative importance of kinetic and thermodynamic parameters in the preparation of these compounds.

There have been reasonable attempts at modifying the hydro/solvothermal methods of synthesizing MOFs. Of these, the microwave-assisted synthesis, ${ }^{7}$ the liquid liquid interface approach, ${ }^{8}$ the electrochemical route, ${ }^{9}$ the sonochemical route ${ }^{10}$ and the mechanochemical method, ${ }^{11}$ etc. are the important and noteworthy ones. Many of the low temperature $\left(\mathrm{T}<100^{\circ} \mathrm{C}\right)$ preparations of MOFs employ the well-established methods for preparing inorganic coordination compounds such as: (i) slow evaporation, (ii) layering of low-boiling organic solvents over the reaction mixture, etc. One of important recent developments in the synthesis of MOFs is the use of high-throughput (HT) methods. ${ }^{12}$ The HT screening, in fact, appears to be an easy and a facile route for the discovery of a large number of compounds in a short span of time. This approach was extensively used in screening a number of zeolitic imidazolate frameworks (ZIF) with great success. ${ }^{12 \mathrm{a}}$

\section{Structure}

The structure is an important aspect in inorganic materials chemistry. Structure of the metal-organic framework determines the nature of the pores, which can be exploited for many important applications. It has been suggested that the formation of a particular structure can be controlled by the careful design of the participating ligands, but in practice it is not very easy. Yaghi and co-workers have employed the close similarity between the $-\mathrm{Si}-\mathrm{O}-\mathrm{Si}$ angles in zeolites to that of the $\mathrm{N}-\mathrm{C}-\mathrm{N}-$ angle in imidazole to prepare a number of zeolite-like imidazolate frameworks (ZIFs). ${ }^{12 a}$ The preparation of ZIFs can be considered as a reasonable success of the design based synthetic approach. The variations in the coordination modes of the participating organic functional groups along with the coordination geometrical preferences of the central metal ions makes it difficult to predict, apriori, the final structure of the MOFs. In spite of these difficulties, there has been considerable progress in identifying important inorganic structures within MOF. Here, we present few examples of the important MOF structures.

The most studied/well known MOF structures are MOF-5, ${ }^{13}$ HKUST-1, ${ }^{14}$ MIL-53, ${ }^{15}$ MIL-101, ${ }^{16}$ etc. Many of these are high symmetry structures and have well connected periodic pore structures. The MOF-5, $\left[\mathrm{Zn}_{4} \mathrm{O}(1,4-\mathrm{bdc})_{3}(\mathrm{DMF})_{8}\left(\mathrm{C}_{6} \mathrm{H}_{5} \mathrm{Cl}\right)\right]$, can be considered as derived from the $\alpha$-Po structure (figure 1a). It has been shown that this structure is amenable to manipulation and can be considered as a generic structure for a family of similar compounds. ${ }^{17}$ The HKUST-1, $\left[\mathrm{Cu}_{3}(\mathrm{btc})_{2}\right]$, on the other hand has a unique structure (figure 1b). It is now possible to synthesize this compound by careful layer-by-layer assembly which can be exploited for many practical purposes. ${ }^{18}$ The MIL (MIL=Materials Institut Lavoisier), is another large family of compounds exhibiting interesting structures. Unlike MOF-5 structure, the MIL-53 structure (figure 1c) is stabilized using a large number of elements of the periodic table. ${ }^{19}$ The representative structures clearly demonstrate the vast potential for structural manipulations; the MOF-5 structures exhibit manipulation of the organic while the MIL structures exhibit the inorganic (elemental) manipulations.

The addition to these structures, the homochiral structures prepared by Kim and co-workers, ${ }^{20}\left[\mathrm{Zn}_{3}\left(\mu_{3}-\mathrm{O}\right)\right.$ $\left.\left(\mathrm{L}_{4}-\mathrm{H}\right)_{6}\right] \cdot 2 \mathrm{H}_{3} \mathrm{O} \cdot 12 \mathrm{H}_{2} \mathrm{O}$, suggest that non-centrosymmetric structure with periodic porosity can be prepared easily. These may find useful applications in chiral reactions and separations and constitute an important development in MOFs. Kitagawa and co-workers recently utilized the concept of mutual recognition of common crystallographic planes with comparable lattice parameters to synthesize hetero structures with MOFs. The compound, $\left[\mathrm{Zn}_{2}(\mathrm{ndc})_{2}\right.$ (dabco)], is used as the core crystal over which the compound, $\left[\mathrm{Cu}_{2}(\mathrm{ndc})_{2}(\mathrm{dabco})\right]$, is grown. This is a completely new concept and represents the first example of a hetero-structure in MOF. Both the phases have the same space group and possess near 


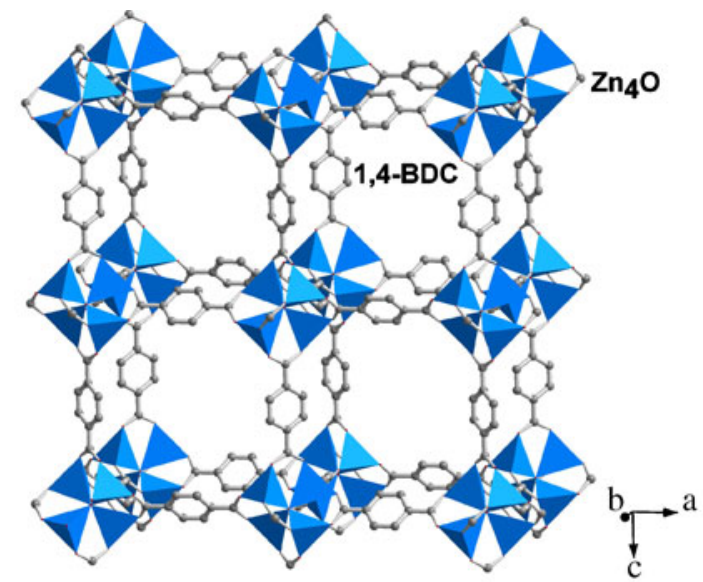

(a)

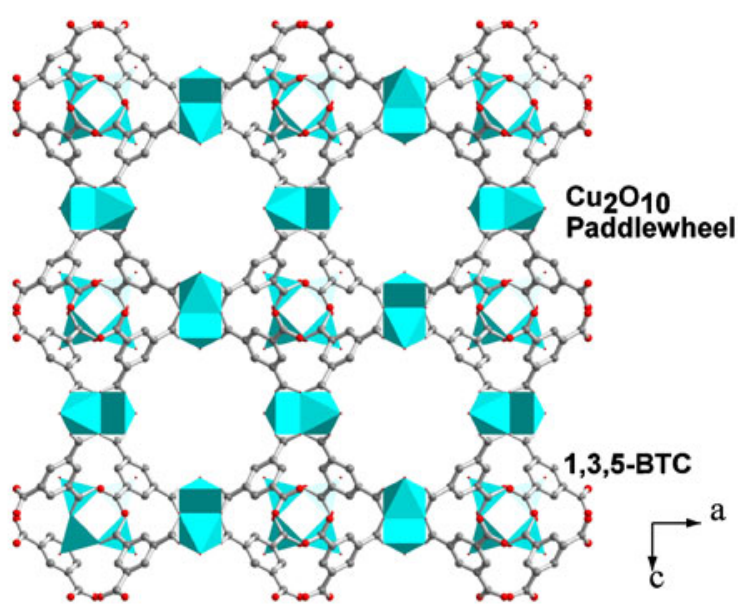

(b)

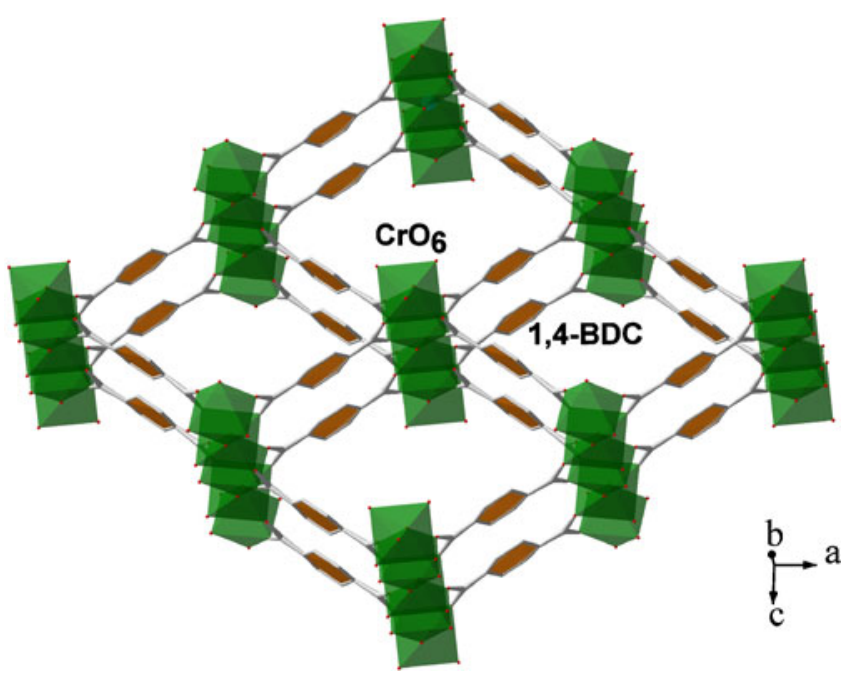

(c)

Figure 1. (a) The structure of MOF-5, showing the connectivity between the $\mathrm{Zn}_{4} \mathrm{O}$ clusters and 1,4-bdc units (ref. 13). (b) View of the structure of HKUST-1, $\left[\mathrm{Cu}_{3}(\mathrm{btc})_{2}\right]$, showing the connectivity between the trimesate and the copper paddlewheel (ref. 14). (c) Figure shows the structure of MIL-53(Cr), $\mathrm{Cr}(\mathrm{OH}) .\left\{\mathrm{O}_{2} \mathrm{C}-\mathrm{C}_{6} \mathrm{H}_{4}-\mathrm{CO}_{2}\right\} .\left\{\mathrm{HO}_{2} \mathrm{C}-\mathrm{C}_{6} \mathrm{H}_{4}-\right.$ $\mathrm{CO}_{2} \mathrm{H}_{0.75}$ (ref. 15). identical lattice parameters, which resulted in reducing the strain at the grain boundary as well as improving the possibility of the epitaxial growth of one phase over the other. ${ }^{21}$ Studies of this nature really opens up research in MOFs and provide avenues for further innovative approaches. It is becoming clear that the MOFs, not only have interesting crystal structures, but also are amenable for manipulations.

\section{Structural modifications}

In addition to synthesizing new compounds exhibiting interesting structures, the MOFs provide opportunities for modifying the structures to suit the properties. The notable feature in many as prepared porous MOF structures is the presence of solvent molecules occluded within the pores/channels, which was also known in many aluminosilicate zeolite structures as well. ${ }^{22}$ The solvent molecules are required to be removed from the pores to have accessible open channels in MOFs. The removals of solvent molecules are, generally, carried out by heating the MOF at higher temperature or under vacuum. During this process the MOFs undergo structural adjustment by shrinking, expanding or distorting upon extraction of the solvent molecules. This dynamic change can also involve the removal of solvent/guest molecules bound to the metal center. Many single-crystal to-single-crystal (SCSC) transformation studies have been carried out to understand the solvent extraction/insertion processes in MOFs. ${ }^{23}$ Such studies are rather difficult to perform in aluminosilicates due to the paucity of the available single crystals. The MOF, on the other hand, provides ideal platform to investigate the structural robustness. The studies of this nature are useful for theoretical investigations in relating the structure with bonding and stability. ${ }^{24}$

The removal of guest molecules from MOFs lead to profound changes in the properties of some of them. Kepert and co-workers have established that the removal and re-insertion of guest molecules in $\mathrm{Fe}_{2}$ (azpy) $(\mathrm{NCS})_{4}$ (guest) gives rise to a magnetic spin crossover phenomena. ${ }^{25}$ The changes in the framework geometry and coordination profoundly affect the electronic nature of the MOF. Similar behaviour has also been observed in $\left[\mathrm{KCo}_{7}(\mathrm{OH})_{3}(\mathrm{ip})_{6}\left(\mathrm{H}_{2} \mathrm{O}\right)_{4}\right] \cdot 12 \mathrm{H}_{2} \mathrm{O}$, where the removal of guest molecules leads to changes in the overall magnetic behaviour of the compound. The dehydrated and the as prepared compounds exhibit field dependence, indicative of possible ferromagnetic correlations. ${ }^{26}$ The response of the dehydrated phase, however, is much weaker compared to the as prepared phase (figure 2). The changes in the coordination around the central metal ions, especially in transition metals, during the 


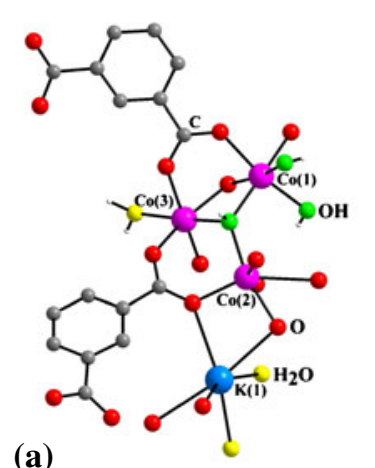

(a)

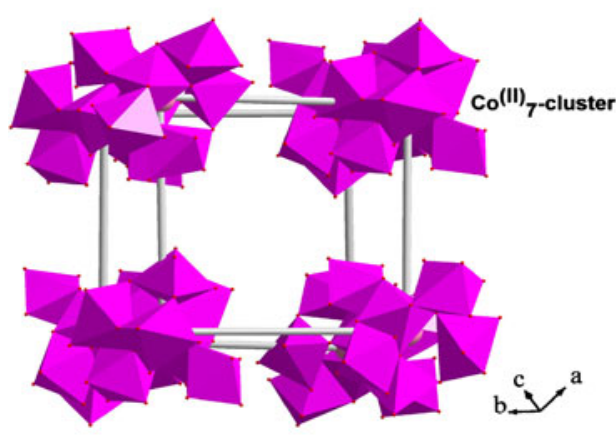

(c)

(d)
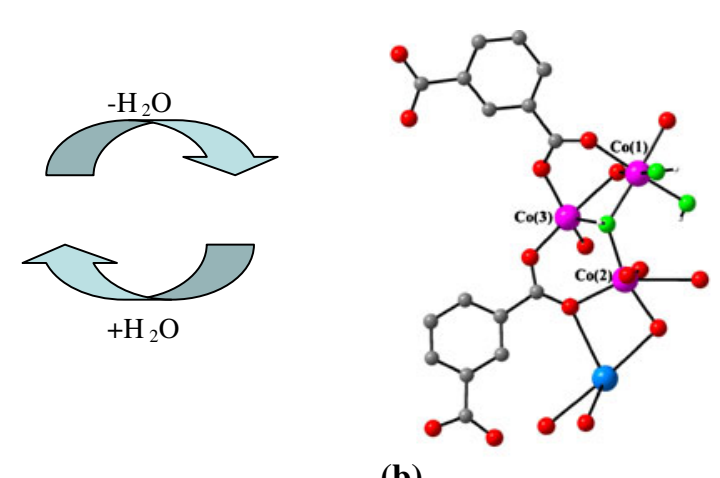

(b)

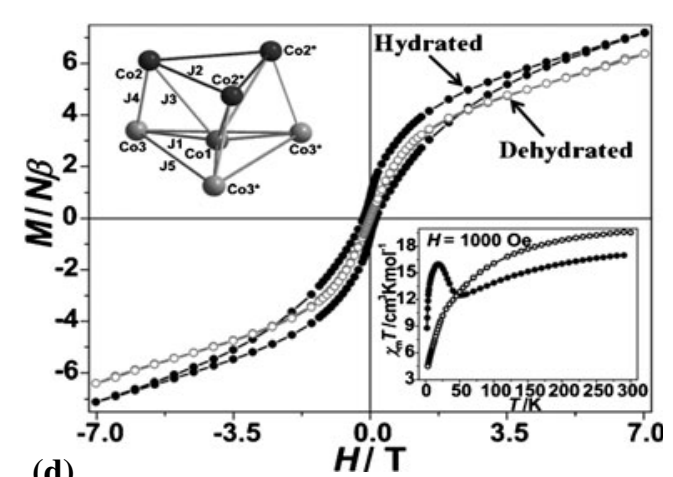

Figure 2. (a) Coordination environment around the $\mathrm{Co}^{2+}$ ions in $\left[\mathrm{KCo}_{7}(\mathrm{OH})_{3}(\mathrm{ip})_{6}\left(\mathrm{H}_{2} \mathrm{O}\right)_{4}\right]$. $12 \mathrm{H}_{2} \mathrm{O}$. (b) The coordination environment in the dehydrated state [note the loss of water molecules on $\mathrm{Co}(3)]$. (c) The connectivity between the heptanuclear cobalt cluster and the isophthalate moiety. (d) Figure shows the magnetization behaviour of the hydrated and dehydrated phase. Inset (upper left) shows the possible exchange pathways between the participating species (Note the small differences in the magnetization behaviour). Inset (lower left) shows the $\chi_{\mathrm{m}} \mathrm{T}-\mathrm{T}$ curves for the hydrated and the dehydrated (ref. 26). Reprinted with permission from ref. 26. Copyright 2007 Wiley - VCH.

removal of the coordinated guest species, can lead to changes in colour in some of MOF structures. This aspect has also been investigated by SCSC transformation studies. ${ }^{27}$ When the guest species happens to be water molecules, the accompanying colour changes in MOF during the dehydration may be exploited for possible use in water sensing. This opens up new possibilities for the use of MOF. ${ }^{27}$

The studies outlined above are inherent in many of the MOF structures. Furthermore, the MOFs are also amenable to modifications employing post-synthetic reactions. In this connection, it may be noted that the mesoporous silica analogues have been subjected to extensive post-synthetic modifications, which were found to be beneficial in their use as catalytic materials. ${ }^{28}$ Covalent post-synthetic modification of MOFs have been carried out with great success. ${ }^{1}$ Some of these studies were carried out to exploit the pores and channels available in MOFs. It is also necessary to carry out post-synthetic modifications so as to avoid possible interference with the functional groups of the organic during the preparation of MOF. In addition, some substitution at the organic part, though desirable, but may be difficult to incorporate in the structure during the synthesis of MOFs can be carried out.

There are many types of post-synthetic modifications that have carried out on MOFs. Here, only select representative examples are discussed. The post-synthetic modification on $\left[\mathrm{Zn}_{3}\left(\mu_{3}-\mathrm{O}\right)(\mathrm{L}-\mathrm{H})_{6}\right] \cdot 2 \mathrm{H}_{3} \mathrm{O} \cdot 12 \mathrm{H}_{2} \mathrm{O}$, (POST-1), where $\mathrm{L}$ is a chiral building unit based on tartaric acid, produced $\mathrm{I}_{3}^{-}$, which were found to be useful for ion exchange and similar reactions. ${ }^{20}$ Of the many MOF compounds, IRMOF-3, $\left[\mathrm{Zn}_{4} \mathrm{O}\left(\mathrm{NH}_{2}-\right.\right.$ bdc $)_{3}$. (DEF $\left.)_{7}\right]$, is one of the most investigated structure. For example, acetylation reactions have been performed on IRMOF - 3 to give rise to the acetylated analogues. The IRMOF - 3 was also found to undergo reactions with isocyanates forming urea-functionalized compounds. ${ }^{29}$ Salicylaldehyde was also employed to modify IRMOF-3. ${ }^{30}$ The amino groups in IRMOF-3 was modified using salicylaldehyde followed by metallation using $\mathrm{NaAuCl}_{4}$ to produce a new compound, IRMOF-3-SI-Au, which appears to exhibit good catalytic behaviour. ${ }^{31}$ The modified MOF was found to be 
active as a single site heterogeneous catalyst for domino coupling, cyclisation of $\mathrm{N}$-protected ethylaniline, aldehyde, and amines. ${ }^{32}$ What is interesting is that the modified MOFs exhibit considerably more catalytic activity when compared to many compounds having anchored $\mathrm{Au}$ species such as $\mathrm{Au} / \mathrm{ZrO}_{2}, \mathrm{Au}^{3+}$ Schiff base complex, and $\mathrm{AuCl}_{3}$. Similar functionalisation of the amino-groups in MOFs have been carried out by other researchers to yield new types of catalytic materials. ${ }^{33}$ In general, the modified MOFs exhibited considerable catalytic behaviour including selectivity due to the modifications of the pore/channel dimension structures. This behaviour is comparable to that observed in mesoporous silica analogues. ${ }^{34}$

The post-synthetic modification on MOFs can also be profitably employed to impart new properties to the MOF compounds. This aspect was elegantly established by Kim and co-workers, who turned an achiral MOF into a chiral one by careful manipulation of the unsaturated metal centers in MIL-101, using L-proline derivatives. ${ }^{35}$ The modified catalysts, CMIL-1 and CMIL-2 were found to exhibit good catalytic behaviour for asymmetric aldol condensation reactions with ee's in the range of $55-80 \%$. From the above, it is clear that the MOFs are versatile as well as amenable for structural modifications.

\section{Properties based on the structure}

MOFs combine the periodic arrangements of inorganic and organic moieties for use in many interesting applications. It is easy to visualize many properties such as magnetism, catalysis, luminescence, etc, which are dependent on the arrangement of the metal atoms in MOFs. In this section, properties which depend on the overall porosity that leads to sorption and separation behaviour are highlighted.

The fast depletion of natural resources such as oil and gas has propelled researchers to look for alternatives which can be utilized as a fuel. In this respect, hydrogen evolved as the leading alternative as well as the green fuel, but the transport and handling has become important issues due to the combustible nature of hydrogen. There are many studies on storage and transport of hydrogen in the literature. ${ }^{36}$ One such option is to explore MOFs as a possible storage reservoir for hydrogen. MOFs possess large open spaces and can exhibit considerable adsorption capabilities. The various studies on many MOFs indicated that the largest uptake of $8.6 \mathrm{wt} \%$ hydrogen was observed under cryogenic conditions and high pressures in
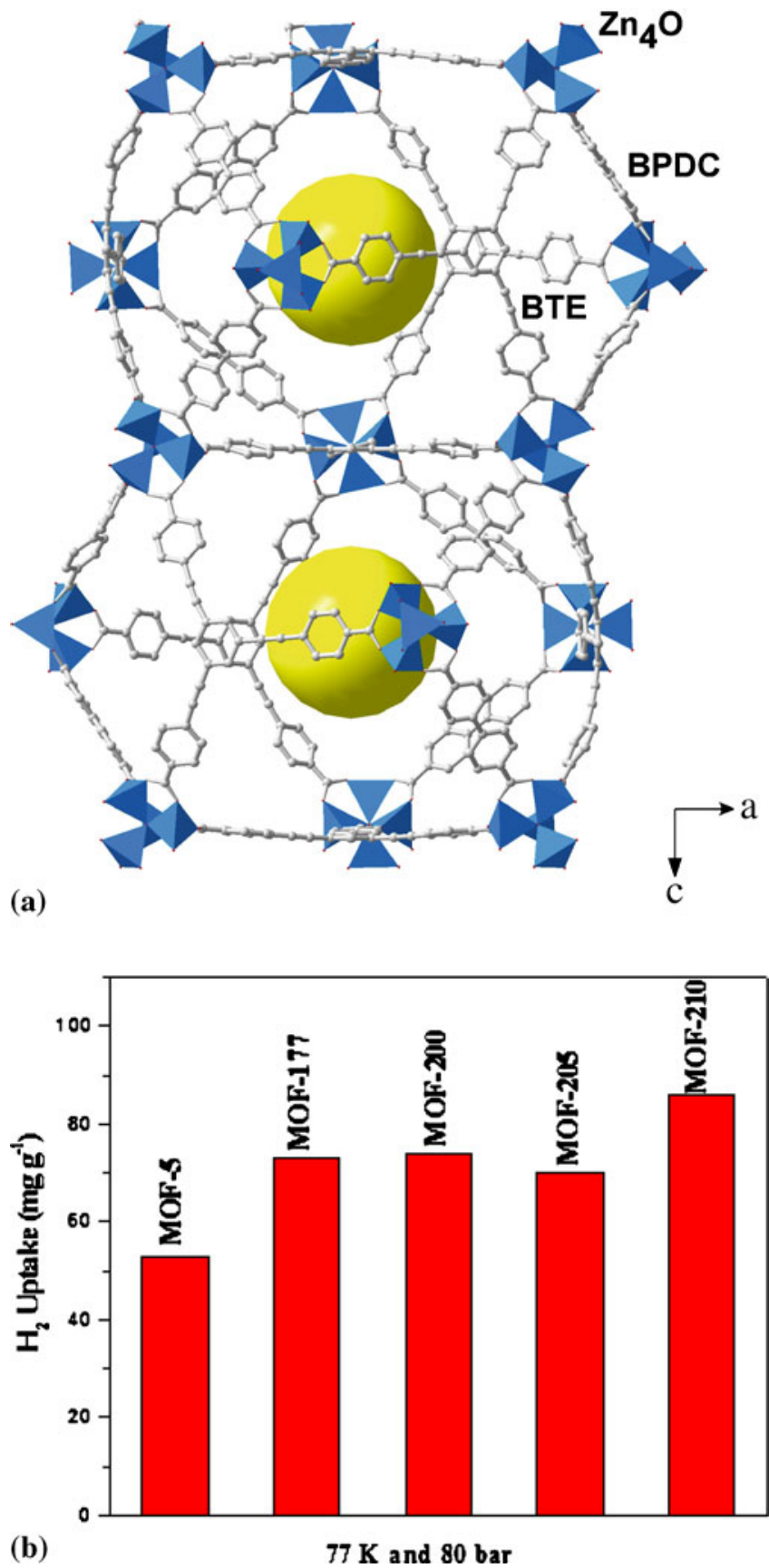

Figure 3. (a) The view of MOF-210, $\mathrm{Zn}_{4} \mathrm{O}(\mathrm{BTE})_{4 / 3}$ (BPDC), showing the large pores available in the structure. (b) The plot shows the amount of hydrogen absorbed in MOF 210 and some well-known MOFs (ref. 37).

$\mathrm{Zn}_{4} \mathrm{O}(\mathrm{BTE})_{4 / 3}(\mathrm{BPDC})\left[\mathrm{BTE}=4,4^{\prime}, 4^{\prime \prime}-\{\right.$ benzene-1,3,5triyl-tris(ethyne-2,1-diyl) $\}$ tribenzoate and $\mathrm{BPDC}=$ biphenyl-4,4'-dicarboxylate], MOF-210 (figure 3). ${ }^{37}$ To improve the hydrogen uptake, many modifications have been attempted. Of these, the use of noble metals on active carbon with MOF is an important upgrade. Thus, for example, the pores/channels of IRMOF-8 were, partially filled with $\mathrm{Pt} / \mathrm{Pd}$ on active carbon, which exhibits a much higher uptake of hydrogen. ${ }^{38}$ Recently, 
Pd nanoparticles are anchored within the MOFs, $\left[\mathrm{Zn}_{3}(\mathrm{ntb})_{2}-(\mathrm{EtOH})_{2}\right] \cdot 4 \mathrm{EtOH}$, to enhance the hydrogen adsorption capacity. ${ }^{39}$ Though considerable progress has been made in the adsorption studies of hydrogen on MOFs, it is not yet feasible to employ MOFs as a viable option/alternative for transporting hydrogen for use as a fuel. More work and new approaches are required to harness the usefulness of MOFs.

The openness of the MOF structure provided unique opportunities to investigate the adsorption behaviour of other important gases such as $\mathrm{CO}_{2}, \mathrm{CH}_{4}$, etc. The various studies clearly establishes that the MOFs provide enhanced as well as selective adsorption for these gas molecules, when compared with aluminosilicate zeolites. ${ }^{40}$

One of the persistent problems with adsorption in the porous media is the selectivity. This is especially true for gases having closely comparable kinetic radii. The MOFs with superior flexible pores can be gainfully employed for possible separation of gas/liquid mixtures having closely related radii. A mixture of vapors of methanol and $\mathrm{CH}_{4}$ can be separated by using a dehydrated MOF, $\left[\mathrm{Cu}_{2}(\mathrm{pzdc})_{2}(\mathrm{dpyg})\right] .8 \mathrm{H}_{2} \mathrm{O} .{ }^{41}$ Here, the hydrophilicity at the metal site was used for the separation. Similarly, the selective adsorption of $\mathrm{CO}_{2}$ over $\mathrm{N}_{2}$ and $\mathrm{CH}_{4}$ was demonstrated by utilizing the size of the window leading to the channels in the MOF, $\mathrm{Mn}$ (formate) $)_{2} .1 / 3$ dioxane. ${ }^{42}$ The mild basicity associated with the framework oxygen atoms was employed to observe the preferential adsorption of acetylene over $\mathrm{CO}_{2}$ in $\mathrm{Cu}_{2}$ (pzdc) $)_{2}$ (pyz). $2 \mathrm{H}_{2} \mathrm{O} .{ }^{43}$ The close kinetic diameter between benzene and cyclohexane posed challenges in their separation. The unusual compound, [Zn(TCNQ-TCNQ)bpy], was found to be very selective for benzene compared to cyclohexane (figure 4). ${ }^{44}$

Kitagawa and co-workers employed HKUST, $\left[\mathrm{Cu}_{3}\right.$ (btc $)_{2}$ ], to demonstrate the selective adsorption behaviour. ${ }^{45}$ On the silica surface originates the hydrophilicity and the number of the silanol moieties increases with decreasing sizes. The nonosized silica with the terminal silanol groups, inside the pores of HKUST exhibits selective adsorption of water, 1-4-dioxane, etc. More importantly, the silica composites appear to adsorb water more readily even at low pressures compared to pure HKUST compound.

The guest-induced structural transformation is a topic of considerable interest, especially for the selective gas adsorption. The pores within MOFs discriminates molecules by their sizes or by specific host-guest interactions. One can manipulate the structure to observe a dynamic closed or open structural transformation, even compounds possessing interpenetrated structures. The guest-induced structural transformation, generally,

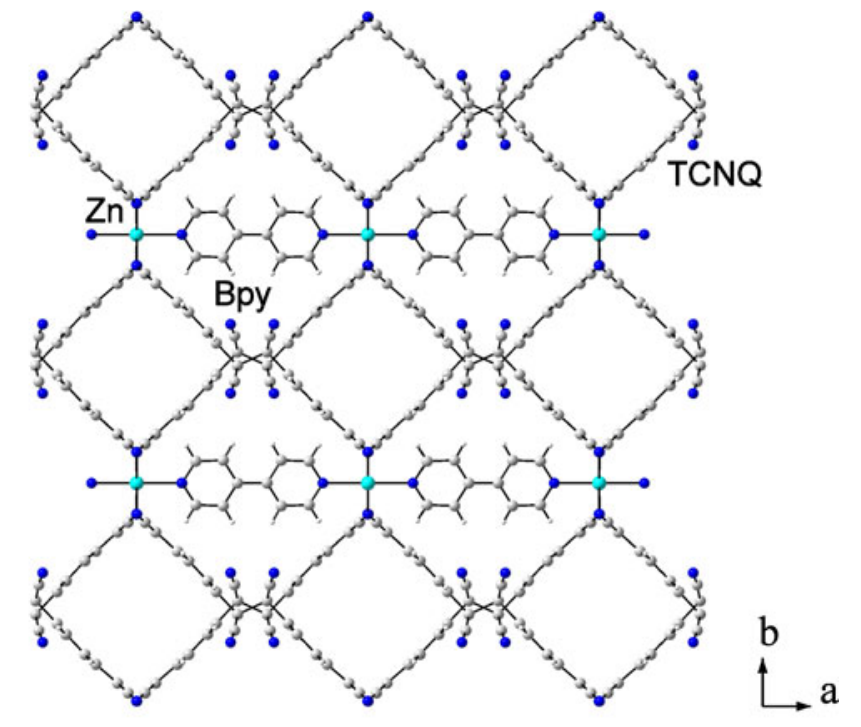

(a)

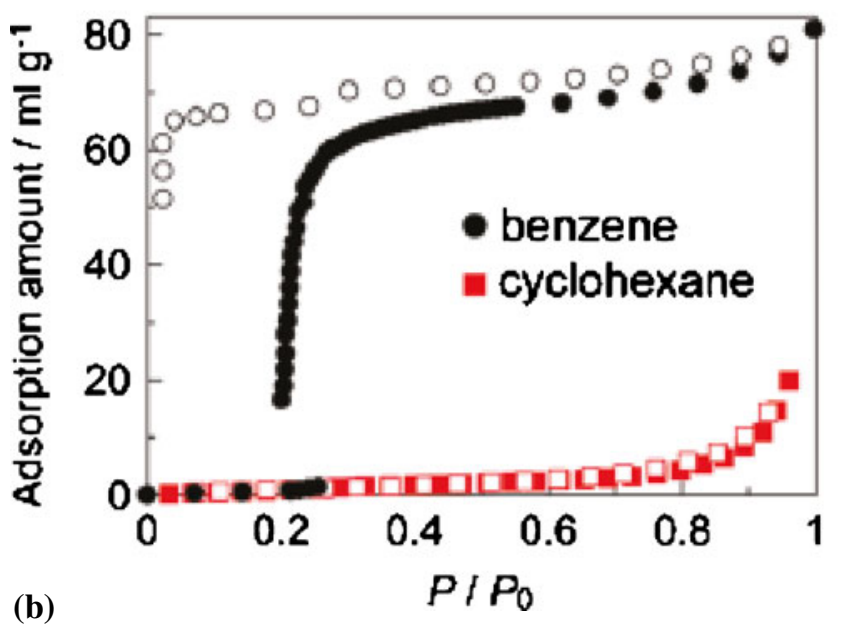

Figure 4. (a) Figure shows the structure of [Zn(TCNQTCNQ)bpy]. Note the presence of smaller channels (ref. 44). (b) The sorption measurements of benzene and cyclohexane at $298 \mathrm{~K}$ on [Zn(TCNQ-TCNQ)bpy]. Note the selective adsorption of benzene (see text). Reprinted with permission from ref. 44. Copyright 2010 American Chemical Society.

results in a step-wise absorption profiles which are known as the gate effect. The gate effect occurs at a particular pressure of the guest molecule and forces the structure to transform from a fully closed structure to an open structure (figure 5a). The observation of such gate effects are more pronounced in compounds possessing flexible linkers as part of the structure. Suh and co-workers have employed this approach and prepared two new MOFs, $\left[\left(\mathrm{Ni}_{2} \mathrm{~L}_{2}\right)(\mathrm{bptc})\right] \cdot 6 \mathrm{H}_{2} \mathrm{O} \cdot 3 \mathrm{DEF}$ and $\left[\left(\mathrm{Ni}_{2} \mathrm{~L}_{4}\right)(\right.$ bptc $\left.)\right] \cdot 14 \mathrm{H}_{2} \mathrm{O}$, where $\mathrm{L}$ is a square-planar $\mathrm{Ni}^{I I}$ macrocyclic linker. The removal of water molecules gives rise to enhanced and selective $\mathrm{CO}_{2}$ adsorption over $\mathrm{N}_{2}, \mathrm{H}_{2}$, and $\mathrm{CH}_{4}$ gases. ${ }^{46}$ At $298 \mathrm{~K}$ and $1 \mathrm{~atm}$, $\left[\left(\mathrm{Ni}_{2} \mathrm{~L}_{2}\right)\right.$ (bptc) $]$ adsorbs $9.2 \mathrm{wt} \%$ of $\mathrm{CO}_{2}$, up to a $\mathrm{P} / \mathrm{P}_{\mathrm{o}}$ 


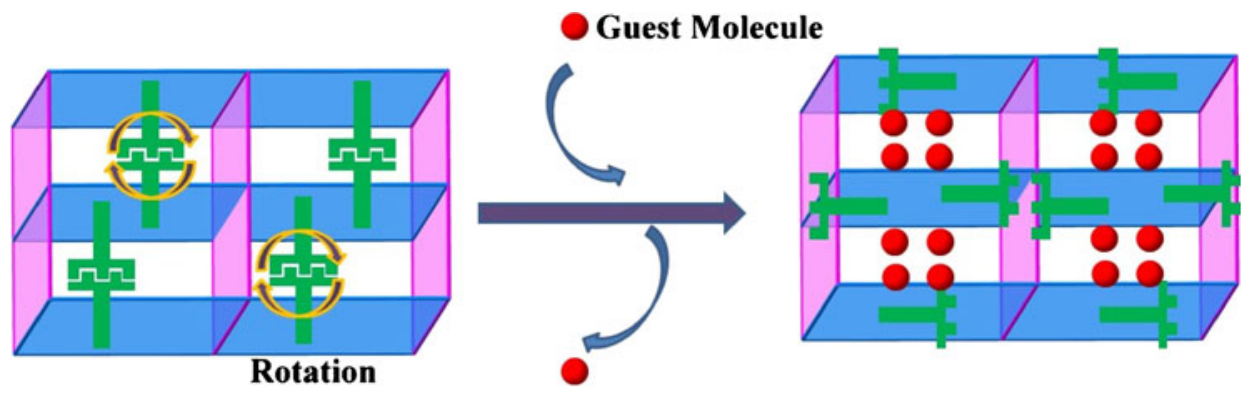

(a)

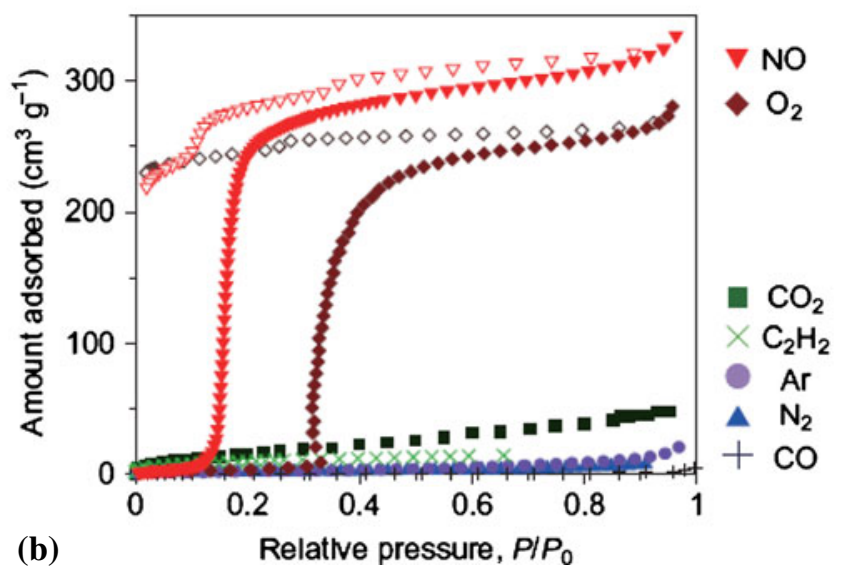

Figure 5. (a) Figure shows the representive mechanism of gate effect in MOFs. (b) The selective sorption measurements of $\mathrm{O}_{2}$ and NO on [Zn(TCNQ-TCNQ)bpy] (ref. 47). Reprinted with permission from ref. 47. Copyright 2010 Nature Publishing Group.

of 0.61 . Above the value of 0.61 , the compounds show an abrupt rise in the adsorption behaviour suggesting that the gate opening pressures in these compounds is likely to be $0.61 \mathrm{~atm}$ at $298 \mathrm{~K}$. The sudden rise in the adsorption also accompanies a structural transformation to open phase. From the studies of that nature, it is clear that the adsorption can be manipulated by force modifications of the structure. It must be understood that the gate-opening in MOF structures are not random, but depends on the adsorbent molecules. This suggest that there are other subtle interactions such as host-guest compatibility, hydrophobic-hydrophilic relationships, etc may be important in determining the gate opening pressure as well as temperature.

Recently, Kitagawa and co-workers expanded this idea further to include charge-transfer interactions for the gate opening in [Zn(TCNQ-TCNQ)bpy]. ${ }^{47}$ This compound exhibits the gate opening behaviour selectively for $\mathrm{NO}$ and $\mathrm{O}_{2}$ over $\mathrm{CO}_{2}, \mathrm{C}_{2} \mathrm{H}_{4}, \mathrm{Ar}, \mathrm{N}_{2}$ and $\mathrm{CO}$, presumably due to the charge-transfer interactions between the adsorbed molecules, $\mathrm{O}_{2}$, NO and the TCNQ ligands (figure 5b).

The recent family of MOFs, the zeolitic imidazolate frameworks (ZIFs) also exhibits peculiarities in the adsorption behaviour, ${ }^{48}$ which may be related to other structural changes. Kapteijn and co-workers observed that $\mathrm{Zn}(\mathrm{PhIM})_{2} \cdot\left(\mathrm{H}_{2} \mathrm{O}\right)_{3}$ ( $\left.\mathrm{ZIF}-7\right)$ exhibit preferential adsorbtion of ethane over ethyne. ${ }^{49}$ The change of the conformation of the benzimidazole was found to be responsible for the observed behaviour. It appears that the adsorption of different species in MOFs require different interactions and even conformational changes. In this respect, the role of organic linkers in MOFs becomes pivotal.

A MOF compound, PIZA-1, [CoT $\left(p-\mathrm{CO}_{2}\right) \mathrm{PPCo}_{1.5}$ $\left.\left(\mathrm{C}_{5} \mathrm{H}_{5} \mathrm{~N}\right)_{3}\left(\mathrm{H}_{2} \mathrm{O}\right)\right] \cdot \mathrm{C}_{5} \mathrm{H}_{5} \mathrm{~N}$, composed of $\mathrm{Co}^{3+}$ porphyrin and trinuclear $\mathrm{Co}^{2+}$-carboxylate clusters was found to be a promising candidate as a desiccant in the drying of the organic solvents such as benzene, toluene, and tetrahydrofuran. In comparison with the traditional desiccant zeolite 4A, this MOF exhibited very good capacity and affinity for water with rapid kinetic behaviour for the sorption of water from the organic solvents. Since this compound is rather unique, size and shape selectivity was also explored, which revealed that the smaller or less sterically bulky molecule was adsorbed preferentially. ${ }^{50}$

MOF-177, $\mathrm{Zn}_{4} \mathrm{O}(\mathrm{BTB})_{2}$. (DEF $)_{15}\left(\mathrm{H}_{2} \mathrm{O}\right)_{3}$, comprised of octahedral basic zinc carboxylate clusters linked by 1,3,5-(triscarboxyphenyl)benzene, demonstrated 
sorption of large molecules. ${ }^{51}$ This MOF has been shown to occlude $\mathrm{C}_{60}$. Three polycyclic organic dyes; Astrazon orange R, Nile red, and Reichardt's dye, were also investigated as adsorbents into MOF-177. The studies indicate Astrazon Orange $\mathrm{R}$ absorbed the maximum followed by Nile red and Reichardt's dye was not even absorbed. Though size dependent adsorption has been well-established in zeolites, the efficacy of MOFs as a good alternative is established by these studies.

As mentioned earlier, the MOF can exhibit chiral structures or can be made chiral by post-synthetic modifications, which can find applications in asymmetric catalysis, chiral separation of molecules, etc. The separation of racemic mixtures of 2-butanol can be achieved using $\left[\mathrm{Cd}(\mathrm{QA})_{2}\right]$, where $\mathrm{QA}$ is a chiral carboxylic acid. ${ }^{52}$ These compounds use the selective adsorption property in which the chirality of the structure and the solvent molecules are matched. A homochiral threedimensional MOF, [ $\mathrm{Zn}_{2}$ (BDC)(l-lac)(DMF)].(DMF), was employed for the sorption of several substituted racemic thioether oxides. ${ }^{53}$ This compound was shown to be effective not only for the separation of chiral enantiomers but also for the size selective adsorption. These studies reiterate the versatility of MOFs.

The loss of coordinated solvent molecules in MOFs have been investigated by many research groups. ${ }^{54}$ The removal of such solvent molecules lead to coordinatively unsaturated metal centers, which can be manipulated for many interesting applications. The loss of coordinated water molecules leading to colour change in $\left[\mathrm{Co}_{2}\left(\mathrm{NH}_{2}-\mathrm{BDC}\right)_{2}\right.$ (pyrazine $\left.)\left(\mathrm{H}_{2} \mathrm{O}\right)_{2}\right] \cdot 3 \mathrm{H}_{2} \mathrm{O}$, has been proposed for use as water sensors. ${ }^{27}$ Morris and coworkers have exploited this aspect of MOFs to anchor NO molecules to the unsaturated metal centers, which can be triggered to release the NO under moist conditions. The medicinal use of NO as a muscle relaxor has been known and this study suggests interesting possibilities for use in bio-medical related applications of MOF. ${ }^{55}$

Bio-medical studies of MOF are important as there are not many bio-compatible solids that can have open pores and absorb/desorb important drug molecules. In this connection, the adsorption/desorption studies of drug molecules on MIL family of compounds could be considered path breaking. ${ }^{56}$ MIL -100 family of compounds exhibit adsorption of ibuprofen and release under biological conditions. The adsorption and release of procainamide, an antiarythmia drug, has been carried out in $\mathrm{Zn}_{8}(\mathrm{ad})_{4}(\mathrm{BPDC})_{6} \mathrm{O} .2 \mathrm{Me}_{2} \mathrm{NH}_{2} .8 \mathrm{DMF} .11 \mathrm{H}_{2} \mathrm{O} .{ }^{57}$ Since this compound was prepared using adenine, it is expected to be safe under biological conditions. The advent and developments in nano materials brought about changes in the way MOFs are investigated. The detection of dipicolinic acid (DPA) was facilitated by functionalized core-shell particles of $\operatorname{Gd}(\mathrm{BDC})_{1.5}$ $\left(\mathrm{H}_{2} \mathrm{O}\right)_{2} @ \mathrm{SiO}_{2} .{ }^{58}$ Similar studies using the $\mathrm{Mn}_{3}(\mathrm{BTC})_{2}$ $\left(\mathrm{H}_{2} \mathrm{O}\right)_{6}$, was found to be beneficial in the direct imaging of angiogenic cancer cells. ${ }^{59}$ Though the MOFs appear to exhibit many interesting bio-properties, the biological related studies were carried out invitro conditions rather than invivo conditions. Much work needs to be carried out to reap the beneficial observations of the MOFs.

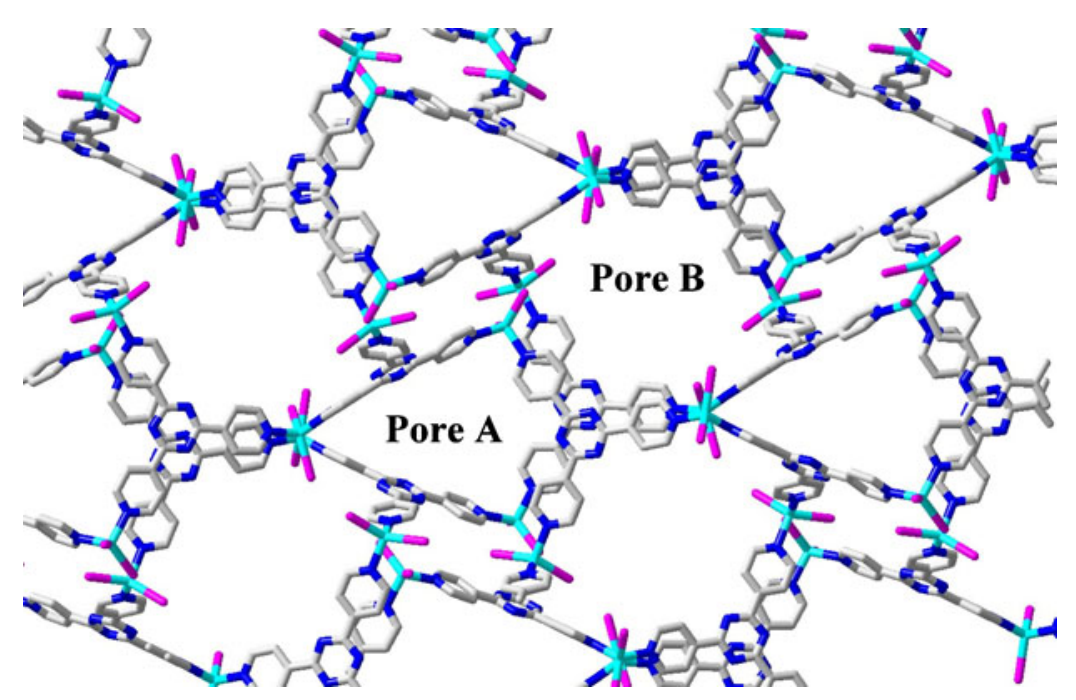

Figure 6. Structure of $\left[\left(\mathrm{ZnI}_{2}\right)_{3}(\mathrm{TPT})_{2}(\right.$ triphenylene $\left.)(\text { Solvent })_{\mathrm{x}}\right](\mathrm{TPT}=$ tris(4-pyridyl) triazine). The guest triphenylene and solvent molecules are not shown for clarity. The figure shows two different kinds of pores (ref. 60). 

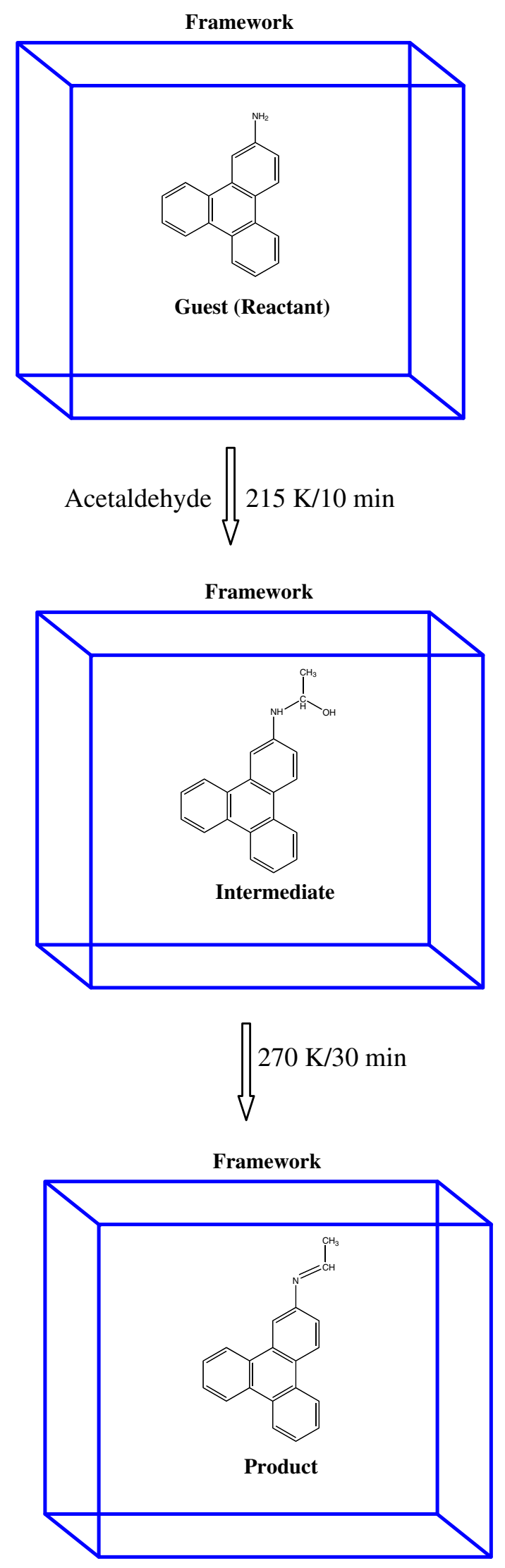

Figure 7. Schematic of the imine formation and trapping of intermediate from acetaldehyde and 1-aminotriphenylene within the pores of $\left[\left(\mathrm{ZnI}_{2}\right)_{3}(\mathrm{TPT})_{2}(1\right.$-aminotriphenylene $)$ (ethyl acetate) $)_{x}$ ] (ref. 61).

\section{Catalysis, luminescence and magnetic behaviour}

During the early 90's, the discovery of meso and macroporous silica provided the first instances of carrying out homogeneous catalysis in heterogeneous environments. ${ }^{34}$ Many important and interesting reactions were carried out within the confined environment provided by the mesoporous-silica. The discovery of MOFs in the sense are the next generation of a class of material that have unique structures. In addition, the free functional groups of the participating organic molecules forming the MOF structures can also be utilized. Fujita and co-workers were the foremost in exploiting this aspect of MOFs (figure 6). ${ }^{60}$ The careful studies carried out by them reveal that the possibility of not only carrying out organic reactions, but also stabilize interesting intermediates and products. ${ }^{61}$ These studies are represented schematically in figure 7 . It has been shown that MOFs can also be employed as a photocatalyst in the UV-assisted decomposition of harmful organic pollutants. It appears that the photoexcitation of the organic ligand and the electron transfer through the metal atom is responsible for the breaking down of the organic. This study highlights another use for the MOFs in environment related applications (figure 8). ${ }^{62}$

Aluminosilicate zeolites have been traditionally employed for use in Bronsted acid catalysis. The MOF structures can have coordinatively unsaturated metal centers, which can act as Lewis acid sites. Thus, MOFs can provide Lewis catalytic reaction centers. Lewis acid catalytic reactions of cyanosilytion of imines have been carried out in MOFs. ${ }^{63}$ Furthermore, many simple organic reactions such as Knoevenagel condensation have also been studied using different aldehydes. ${ }^{64}$ Important organic reactions involving $\mathrm{C}-\mathrm{C}$ coupling, aerobic oxidation and hydrogenation reactions were found to be catalysed by the MOF, [Pd(2-pymo)2] (2-pymo $=2$-hydroxypyrimidinolate) ${ }^{65}$ It is likely that the structure is flexible to accommodate partial reduction of $\mathrm{Pd}^{I I}$ to $\mathrm{Pd}^{0}$ during the catalytic reactions, though there are no experimental proof for this hypothesis. Acyl transfer reactions have also been carried out using $\mathrm{ZnPO}-\mathrm{MOF}, \quad\left[\mathrm{Zn}_{2}\{1,2,4,5\right.$-tetrakis(4-carboxyphenyl) benzene $\}\{Z n-5,15-D i p y r i d y l-10,20 \quad$ bis(pentafluorophenyl))porphyrin \}].2DMF (figure 9). This catalytic reaction exhibits very high activity. ${ }^{66}$

The theories of magnetism and magnetic behaviour are abound in the literature. The validity of some of the theoretical proposals require model compounds, which are not many. The MOFs can be prepared by careful manipulation of the reactants and such designed MOFs can act as good model compounds to verify some of the 


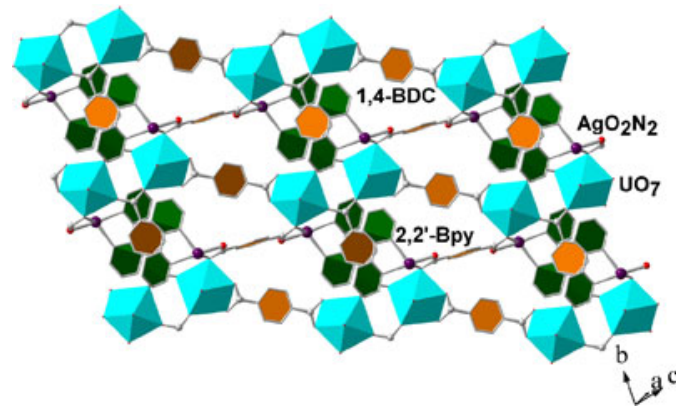

(a)

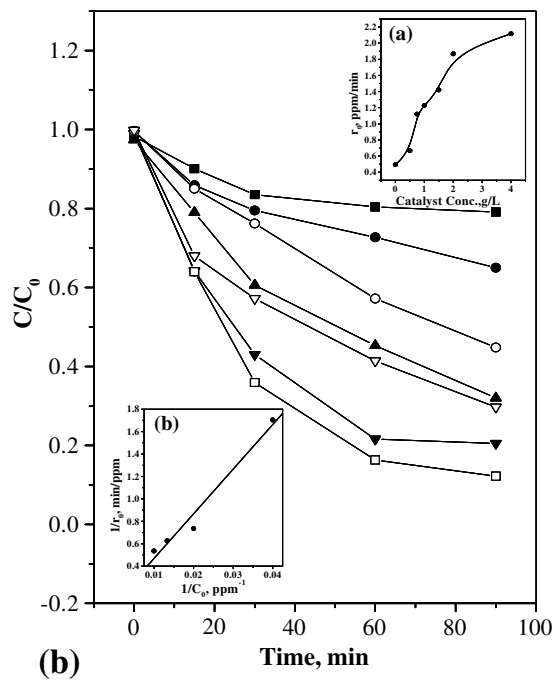

(b)

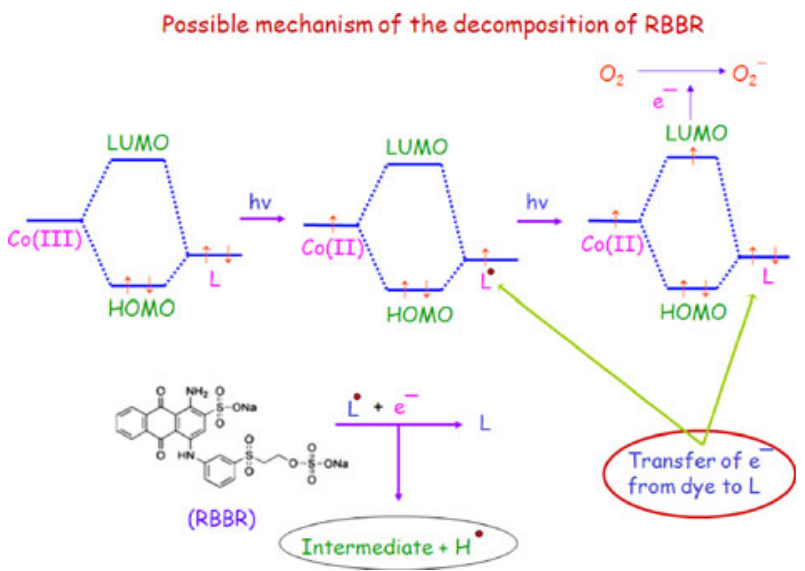

(c)

Figure 8. (a) View of the structure of $\left[\mathrm{Ag}(\mathrm{bpy})\left(\mathrm{UO}_{2}\right)_{2}(\mathrm{bdc})_{1.5}\right]$ (ref. 62). (b) The photocatalytic degradation of organic dyes on $\mathrm{Gd}\left(\mathrm{H}_{2} \mathrm{O}\right) \mathrm{Co}\left[\mathrm{C}_{5} \mathrm{~N}_{1} \mathrm{H}_{3}(\mathrm{COO})_{2}\right]_{2}$. Reprinted with permission from ref. 62b. Copyright 2005 Royal Society of Chemistry. (c) The possible general mechanism for the decomposition of dyes using UV - radiation.

well-established theoretical models for the understanding of the magnetic interactions. For example, the presence of infinite $-\mathrm{M}-\mathrm{O}-\mathrm{M}$ - linkages within MOFs either as one-dimensional chains or two-dimensional layers can be used to study and understand the correlation between the structure and the magnetic property. The exchanges through the carboxylate bridges linking the metal centers can affect the magnetic behaviour depending on whether the bridging is syn-syn, syn-anti or anti-anti arrangement. It has been observed that the syn-syn and anti-anti bridges favour antiferromagnetic interactions, whereas the syn-anti bridges favours ferromagnetic ones. ${ }^{1}$ This has been explored and investigated in many MOF structures.

One of the important approaches for realizing porous magnetic MOF is to employ stable organic-free radicals as linkers between the metal centers. This concept was realized by Veciana and co-workers in the isolation of the magnetic MOF, $\mathrm{Cu}_{3}(\mathrm{PTMTC})_{2}(\mathrm{py})_{6}\left(\mathrm{CH}_{3} \mathrm{CH}_{2} \mathrm{OH}\right)_{2}$ $\left(\mathrm{H}_{2} \mathrm{O}\right) .{ }^{67}$ The organic-free radical act as an excellent communicator of the magnetic interactions between the metal centers, through super-super exchange mechanism. Magnetic interactions through simple super-exchange interactions leading to ferri and antiferromagnetic behaviour in MOFs have been well-established. ${ }^{68}$ A classic example of a 2D ferromagnet having weak coupling between the layers was established in the cobalt compound, $\quad\left[\mathrm{Co}_{2}\left(\mu_{3}-\mathrm{OH}\right)\left(\mu_{2}-\mathrm{H}_{2} \mathrm{O}\right)(\right.$ pyrazine $)(\mathrm{OBA})$ $(\mathrm{OBAH})]\left(\mathrm{OBA}=4,4^{\prime}\right.$-oxybis(benzoate). ${ }^{69}$ Here, the structure consists of $\mathrm{Co}_{4}$ buterfly clusters connected by pyrazine forming extended 2D layers, which are pillared by the oxy-bisbenzoate anions. The various components are positioned in a body centered arrangement, which is rarely observed in MOF structures (figure 10). Magnetic kagome lattice based MOF structures have also been reported. Some of these 

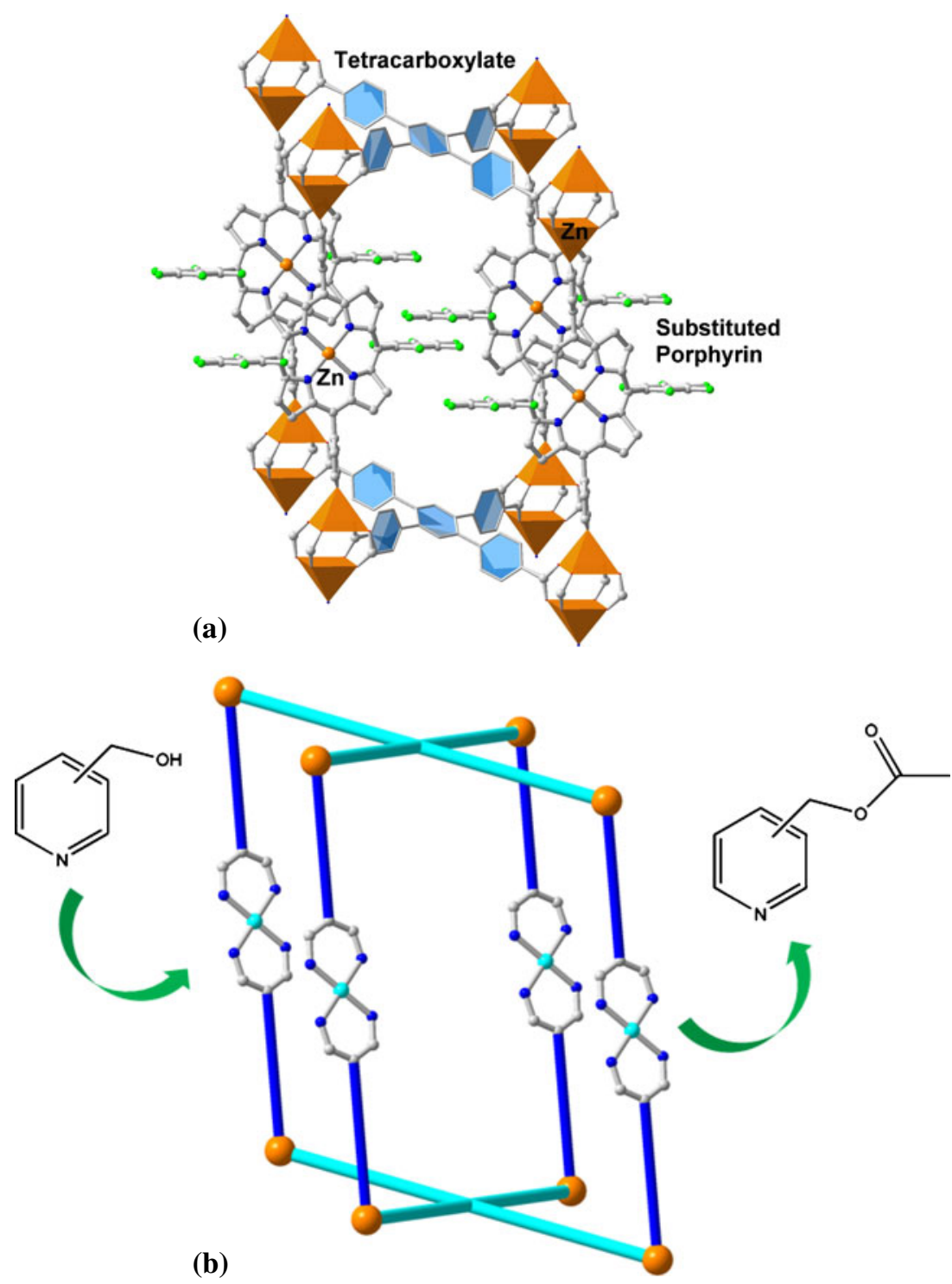

Figure 9. (a) View of the structure of $\mathrm{ZnPO}$ - MOF. (b) Schematic of the acyl transfer reactions in $\mathrm{ZnPO}-\mathrm{MOF}$ (ref. 66).

compounds exhibit spin-canted frustration and interesting magnetic behaviour. ${ }^{70}$ The investigations of this nature provide vital data for the understanding and validation of the available magnetic models.

The study of luminescence behaviour in MOFs is another active area of research. ${ }^{1}$ The various studies point to the observation of three types of luminescent behaviour: (i) intra-ligand luminescence, (ii) ligand to metal charge transfer (LMCT), and (iii) ligand sensitized metal centre luminescence. A large number of $3 \mathrm{~d}$ elements have been employed to investigate the ligand luminescence. The most commonly reported MOF structures are based on $\mathrm{Zn}^{2+}$ and $\mathrm{Cd}^{2+}$ ions, which have filled $\mathrm{d}$ orbitals and thus $\mathrm{d}-\mathrm{d}$ transitions are not possible. In these compounds intra-ligand and/or LMCT effects have been observed. The lanthanide ions have been investigated for the studies of ligand sensitized metal centre luminescence. This is especially true for the $\mathrm{Eu}^{3+}$ and $\mathrm{Tb}^{3+}$ containing MOFs due to their strong narrow emissions in the red and the green region. The $\mathrm{Eu}^{3+}$ containing MOFs exhibit the ${ }^{5} \mathrm{D}_{0} \rightarrow$ ${ }^{7} \mathrm{~F}_{J}$ transition, whereas the $\mathrm{Tb}^{3+}$ containing MOFs exhibit ${ }^{5} \mathrm{D}_{4} \rightarrow{ }^{7} \mathrm{~F}_{J}$ transitions. $\mathrm{Eu}^{3+}$ and $\mathrm{Tb}^{3+}$ doped $\left[\mathrm{M}_{2}-\left(\mathrm{H}_{2} \mathrm{O}\right)_{4}\right]\left[\left\{\mathrm{C}_{5} \mathrm{H}_{3} \mathrm{~N}(\mathrm{COO})_{2}\right\}_{2}\left\{\mathrm{C}_{6} \mathrm{H}_{4}-(\mathrm{COO})_{2}\right\}\right]$ exhibits characteristic luminescence (figure 11). ${ }^{71}$ The photoluminescence studies are important to understand the charge-transfer pathways. When the lanthanide ion is $\mathrm{Nd}^{3+}$, a two-photon up-conversion process has been observed. The studies on the luminescence behaviour in MOFs clearly indicate that the energy transfer from the organic ligands to the metal center is facile. The life-time studies also suggest that the excited state 


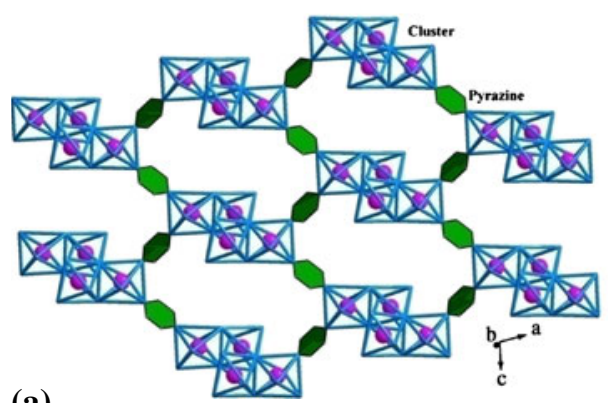

(a)

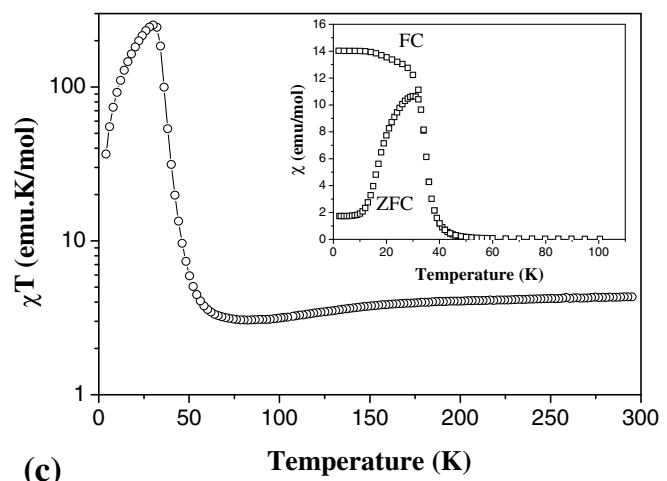

(c)

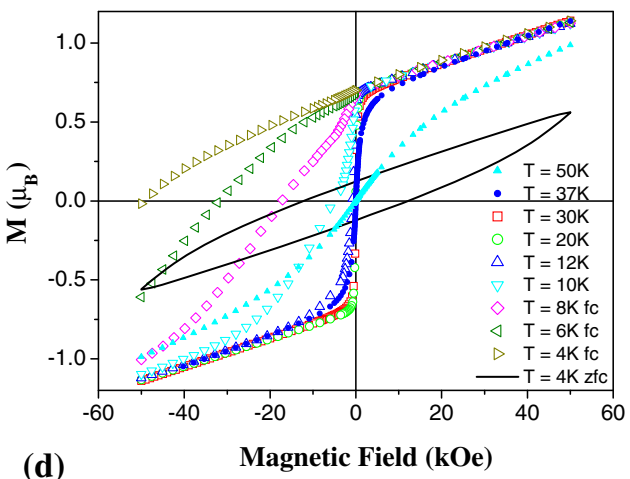

Figure 10. (a) View of the two-dimensional connectivity between the $\left[\mathrm{Co}_{4}\right]$ clusters and the pyrazine molecules in $\left[\mathrm{Co}_{2}\left(\mu_{3}-\mathrm{OH}\right)\left(\mu_{2}-\mathrm{H}_{2} \mathrm{O}\right)(\right.$ pyrazine $\left.)(\mathrm{OBA})(\mathrm{OBAH})\right]$ (ref. 69). (b) The bcc arrangement of the $\mathrm{Co}_{4}$ units. (c) The temperature dependence of the $\chi \mathrm{T}-\mathrm{T}$ plots for $\left[\mathrm{Co}_{2}\left(\mu_{3}-\mathrm{OH}\right)\left(\mu_{2}-\mathrm{H}_{2} \mathrm{O}\right)(\right.$ pyrazine $\left.)(\mathrm{OBA})(\mathrm{OBAH})\right]$. Inset: The temperature variation of the $\mathrm{FC} / \mathrm{ZFC}$ data. (d) Magnetization curves $\mathrm{M}(\mathrm{H})$ at different temperatures for $\left[\mathrm{Co}_{2}\left(\mu_{3}-\mathrm{OH}\right)\left(\mu_{2}-\right.\right.$ $\left.\mathrm{H}_{2} \mathrm{O}\right)$ (pyrazine)(OBA) $\left.(\mathrm{OBAH})\right]$ at various temperature. Reprinted with permission from ref. 69. Copyright 2009 American Chemical Society.

possess considerable stability and allows for exploitation in many important applications.

The MOF compounds have both the inorganic as well as the organic components. Thus, on heating in air/oxygen, the organic part is burnt off leaving behind simple oxides of the participating metal atoms. Depending on the temperature of the decomposition, one can visualize the formation of metal oxides with different particle sizes. If the MOF was synthesized using mixed metals, one can anticipate the formation of complex inorganic oxides with well-established structures. The formation of mixed metal oxides with perovskite $\left(\mathrm{ABO}_{3}\right)^{62 \mathrm{~b}}$ and spinel $\left(\mathrm{AB}_{2} \mathrm{O}_{4}\right)^{72}$ structures have been observed at relatively low temperatures $\left(\sim 300-700^{\circ} \mathrm{C}\right)$. These mixed-metal oxides are, generally, prepared employing ceramic methods at high temperatures $\left(>1000^{\circ} \mathrm{C}\right)$. In addition, it was observed that the mixed-metal oxides form particle sizes that are very small $(\sim 10-20 \mathrm{~nm})$. It has been proposed that the molecular level arrangement of the different elements in the MOF structures would act as a good single source precursor. The mixed-metal nano particles also exhibit excellent magnetic, catalytic and photophysical properties. These observations suggest that the MOFs can provide new vistas for research in the area of functional ceramic solids.

\section{Conclusions and prospects}

The studies on MOFs have been increasing steadily over the years, especially during the last decade, encompassing the different aspects of inorganic materials chemistry. Integration as well as hybridization with other areas of research is important and inevitable for the development of MOFs. Such integration is likely to exploit the mutual benefits of the field and also lead to the generation of other new areas for research. It is apparent that the MOFs hold much promise. The manipulation that are possible in the synthesis and structure, availability of coordination site on metals, good flexibility of the structure coupled with porosity, etc. are some of the reasons for this optimism. The scope for research in this area is not limited by nature, since the number of possible hypothetical structures could be infinite. ${ }^{4,5 a}$ One need to think out-of-the box 


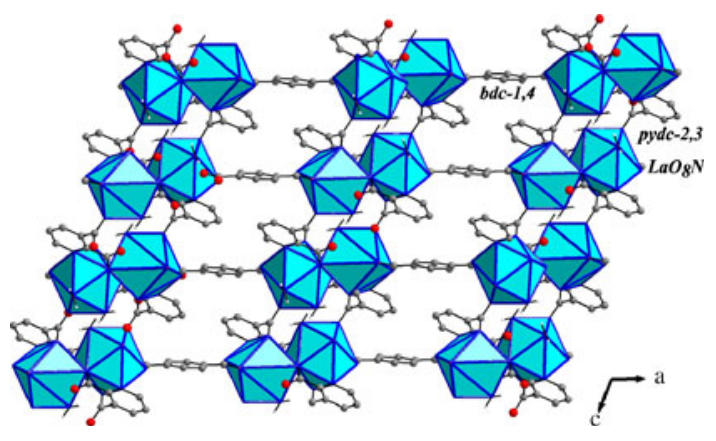

(a)

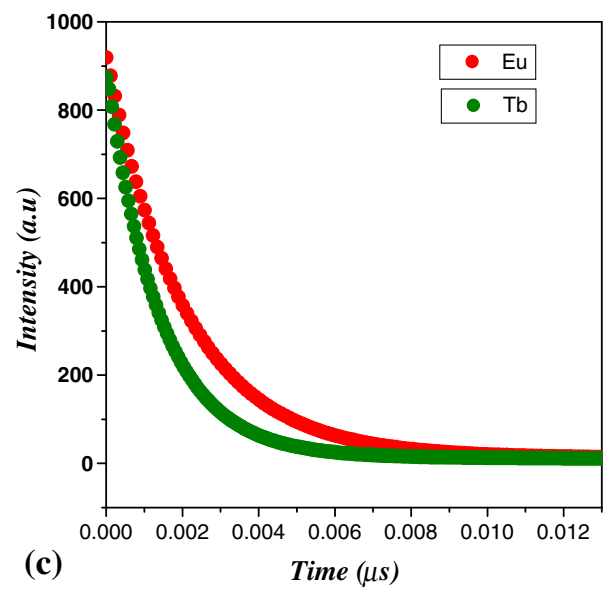

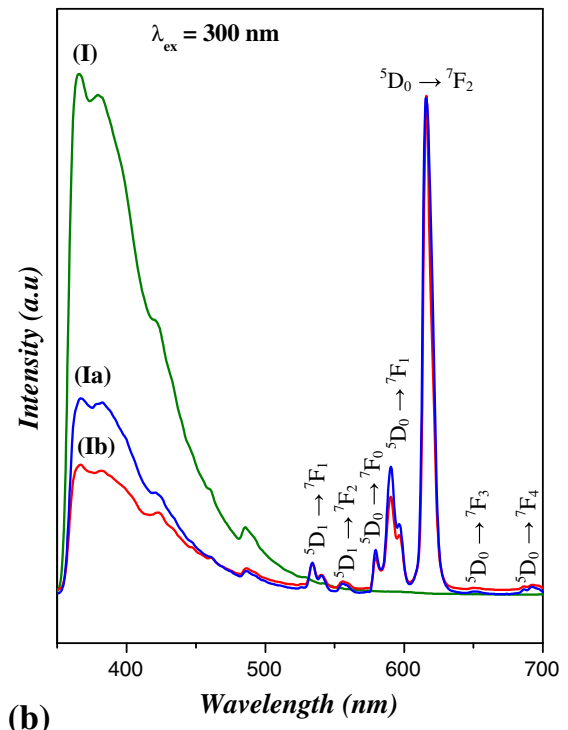

(b)

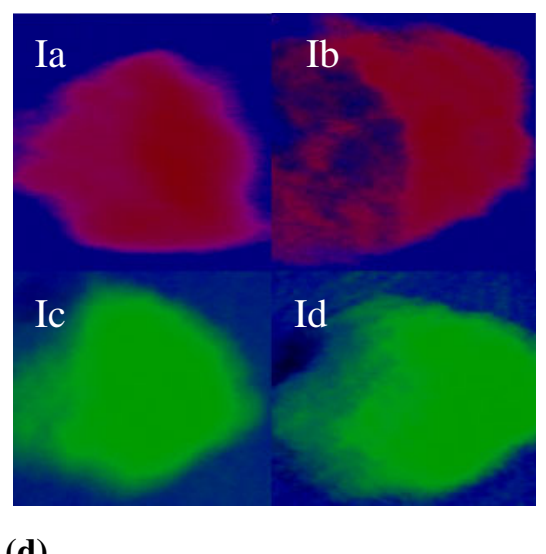

(d)

Figure 11. (a) View of the 3-D structure of $\left[\mathrm{La}_{2}\left(\mathrm{H}_{2} \mathrm{O}\right)_{4}\right]\left[\left\{\mathrm{C}_{5} \mathrm{H}_{3} \mathrm{~N}(\mathrm{COO})_{2}\right\}_{2}\left\{\mathrm{C}_{6} \mathrm{H}_{4}(\mathrm{COO})_{2}\right\}\right]$. (b) The room-temperature photoluminescence spectra of the pure lanthanum compound and the corresponding Eu-doped compounds. (c) Luminescence decay curves of $4 \mathrm{~mol} \% \mathrm{Eu}$ and 4\% Tb-doped sample.(d) View of the Eu-doped samples under UV illumination. Note the distinct colours (ref. 71).

in utilizing these materials profitably towards preparing some of the hypothetical structures. It is desirable to tune the basic properties of MOFs such as gas-storage, gas-separation, etc. with other properties that depend on the behaviour of the electrons such as conductivity, magnetism, spin-crossover, and electro-chromism would be an important challenge. The compounds that can possess the combined behaviour would lead the next-generation of materials in the area of inorganic material chemistry.

\section{Acknowledgements}

SN thanks the Department of Science and Technology (DST), Government of India, for the award of a research grant and the authors also thank the Council of Scientific and Industrial Research (CSIR), Government of India, for the award of a fellowship to DS and a research grant. SN also thanks the Department of Science and Technology, Government of India, for the award of the Raja, Ramanna Fellowship.

\section{References}

1. Special Issue on MOF 2009 Chem. Soc. Rev. 381201

2. (a) Horike S, Shimomura S and Kitagawa S 2009 Nat. Chem. 1 695; (b) Tranchemontagne D J, Ni Z, O'Keeffe $\mathrm{M}$ and Yaghi O M 2008 Angew. Chem. Int. Ed. 47 5136; (c) Férey G, 2008 Chem. Soc. Rev. 37 191; (d) Kitagawa S, Kitaura R and Noro S -I 2004 Angew. Chem., Int. 
Ed. 43 2334; (e) Yaghi O M, O'Keeffe M, Ockwig N W, Chae H K, Eddaoudi M and Kim J 2003 Nature 423705

3. MacGillivray L R 2010 Metal-organic frameworksdesign and applications, Hoboken, NJ: John Wiley and Sons

4. Natarajan S and Mahata P 2009 Chem. Soc. Rev. 382304

5. (a) Wells A F 1977 Three-dimensional nets and polyhedra, New York: John Wiley and Sons; (b) O'Keefe M and Hyde B G 1980 Phil. Trans. 295553

6. (a) Forster P M, Stock N and Cheetham A K 2005 Angew. Chem., Int. Ed. 44 7608; (b) Mahata P, Prabu M and Natarajan S 2008 Inorg. Chem. 478451

7. Kitagawa S, Okubo T, Kawata S, Kondo M, Katada M and Kobayashi H 1995 Inorg. Chem. 344790

8. (a) Bhattacharya S, Sanyal U and Natarajan S 2011 Cryst. Growth Des. 11 735; (b) Banerjee A, Mahata P and Natarajan S 2008 Eur. J. Inorg. Chem. 3501

9. Mueller U, Schubert M, Teich F, Puetter H, SchierleArndt K and Pastre J 2006 J. Mater. Chem. 16626

10. Son W -J, Kim J, Kim J and Ahn W -S 2008 Chem. Commun. 6336

11. Klimakow M, Klobes P, Thuenemann A F, Rademann K and Emmerling F 2010 Chem. Mater. 225216

12. (a) Banerjee R, Phan A, Wang B, Knobler C, Furukawa H, O'Keeffe M and Yaghi O M 2008 Science 319 939; (b) Sarma D, Ramanujachary K V, Stock N and Natarajan S 2011 Cryst. Growth Des. 111357

13. Li H, Eddaoudi M, O’Keeffe M and Yaghi O M 1999 Nature $\mathbf{4 0 2} 276$

14. Chui S S Y, Lo S M F, Charmant J P H, Orpen A G and Williams I D 1999 Science 2831148

15. Serre C, Millange F, Thouvenot C, Nogues M, Marsolier G, Louer D and Ferey G 2002 J. Am. Chem. Soc. 124 13519

16. Férey G, Mellot-Draznieks C, Serre C, Millange F, Dutour J, Surble S and Margiolaki I 2005 Science 309 2040

17. Britt D, Tranchemontagne D and Yaghi O M 2008 Proc. Natl. Acad. Sci. U.S.A. 10511623

18. Shoaee M, Anderson M W and Attfield M P 2008 Angew. Chem., Int. Ed. 478525

19. (a) Ferey G, Latroche M, Serre C, Millange F, Loiseau T and Percheron-Guegan A 2003 Chem. Commun. 2976; (b) Hamon L, Serre C, Devic T, Loiseau T, Millange F, Ferey G and Weireld G De 2009 J. Am. Chem. Soc. 131 8775

20. Seo J S, Whang D, Lee H, Jun S I, Oh J, Jeon Y J and Kim K 2000 Nature 404982

21. Furukawa S, Hirai K, Nakagawa K, Takashima Y, Matsuda R, Tsuruoka T, Kondo M, Haruki R, Tanaka D, Sakamoto H, Shimomura S, Sakata O and Kitagawa S 2009 Angew. Chem., Int. Ed. 481766

22. Baerlocher Ch, McCusker L B and Olson D H 2007 Atlas of zeolite framework types. Zurich, Switzerland: Elsevier

23. (a) Ghosh S K, Bureekaew S and Kitagawa S 2008 Angew. Chem., Int. Ed. 47 3403; (b) Zhang Y -J, Liu T, Kanegawa S and Sato O 2009 J. Am. Chem. Soc. 131 7942

24. Yang L -M, Vajeeston $\mathrm{P}$, Ravindran $\mathrm{P}$, Fjellvag $\mathrm{H}$ and Tilset M 2010 Inorg. Chem. 4910283
25. Halder G J, Kepert C J, Moubaraki B, Murray K S and Cashion J D 2002 Science 2981762

26. Cheng X, Zhang W X, Lin Y Y, Zheng Y Z and Chen X M 2007 Adv. Mater. 191494

27. Sarma D, Ramanujachary K V, Lofland S E, Magdaleno T and Natarajan S 2009 Inorg. Chem. 4811660

28. (a) Thomas J M and Klinowski J 2007 Angew. Chem., Int. Ed. 46 7160; (b) Raja R and Thomas J M 2002 J. Mol. Catal. A 1813

29. Dugan E, Wang Z, Okamura M, Medina A and Cohen S M 2008 Chem. Commun. 3366

30. Ingleson M J, Barrio J P, Guilbaud J B, Khimyak Y Z and Rosseinsky M J 2008 Chem. Commun. 2680

31. Zhang X, Llabrés i Xamena F X and Corma A $2009 \mathrm{~J}$. Catal. 265155

32. Corma A, Iglesias M, Llabrés i Xamena F X and Sánchez F 2010 Chem. Eur. J. 169789

33. Tanabe K K and Cohen S M 2009 Angew. Chem., Int. Ed. 487424

34. Thomas J M, Raja R and Lewis D W 2005 Angew. Chem., Int. Ed. 446456

35. Banerjee M, Das S, Yoon M, Choi H J, Hyun M H, Park S M, Seo G and Kim K 2009 J. Am. Chem. Soc. 131 7524

36. Yang J, Sudik A, Wolverton C and Siegel D J 2010 Chem. Soc. Rev. 39656 and references therein

37. Furukawa H, Ko N, Go Y B, Aratani N, Choi S B, Choi E, Yazaydin A O, Snurr R Q, O'Keeffe M, Kim J and Yaghi O M 2010 Science 329424

38. Li Y and Yang R T 2006 J. Am. Chem. Soc. 128726

39. Cheon Y E and Suh M P 2009 Angew. Chem., Int. Ed. 482899

40. D’Alessandro D M, Smit B and Long J R 2010 Angew. Chem., Int. Ed. 496058

41. Kitaura R, Fujimoto K, Noro S, Kondo M and Kitagawa S 2002 Angew. Chem., Int. Ed. 41133

42. Dybtsev D N, Chun H, Yoon S H, Kim D and Kim K 2004 J. Am. Chem. Soc. 12632

43. Matsuda R, Kitaura R, Kitagawa S, Kubota Y, Belosludov R V, Kobayashi T C, Sakamoto H, Chiba T, Takata M, Kawazoe Y and Mita Y 2005 Nature 436 238

44. Shimomura S, Matsuda R and Kitagawa S 2010 Chem. Mater. 224129

45. Uemura T, Kadowaki Y, Kim C R, Fukushima T, Hiramatsu D and Kitagawa S 2011 Chem. Mater. 231736

46. Choi H -S and Suh M P 2009 Angew. Chem., Int. Ed. 48 6865

47. Shimomura S, Higuchi $M$, Matsuda R, Yoneda $\mathrm{K}$, Hijikata Y, Kubota Y, Mita Y, Kim J, Takata M and Kitagawa S 2010 Nature Chem. 2633

48. Hayashi H, Cote A P, Furukawa H, O'Keeffe M and Yaghi O M 2007 Nat. Mater. 6501

49. Gucuyener C, van den Bergh J, Gascon J and Kapteijn F 2010 J. Am. Chem. Soc. 13217704

50. Kosal M E, Chou J H, Wilson S R and Suslick K S 2002 Nat. Mater. 1118

51. Chae H K, Siberio-Perez D Y, Kim J, Go Y, Eddaoudi M, Matzger A J, O'Keeffe M and Yaghi O M 2004 Nature 427523

52. Xiong R, You X, Abrahams B F, Xue Z and Che C M 2001 Angew. Chem. Int. Ed. 404422 
53. Dybtsev D N, Nuzhdin A L, Chun H, Bryliakov K P, Talsi E P, Fedin V P and Kim K 2006 Angew. Chem., Int. Ed. 45916

54. (a) Aslani A and Morsali A 2008 Chem. Commun. 3402; (b) Rather B and Zaworotko M J 2003 Chem. Commun. 830

55. McKinlay A C, Xiao B, Wragg D S, Wheatley P S, Megson I L and Morris R E 2008 J. Am. Chem. Soc. 130 10440

56. Horcajada P, Serre C, Vallet-Regi M, Sebban M, Taulelle F and Ferey G 2006 Angew. Chem., Int. Ed. 45 5974

57. An J, Geib S J and Rosi N L 2009 J. Am. Chem. Soc. 131 8376

58. Rieter W J, Taylor K M L and Lin W 2007 J. Am. Chem. Soc. 1299852

59. Taylor K M L, Rieter W J and Lin W 2008 J. Am. Chem. Soc. 13014358

60. Ohmori O, Kawano M and Fujita M 2005 Angew. Chem., Int. Ed. 441962

61. Kawamichi T, Haneda T, Kawano M and Fujita M 2009 Nature 461633

62. (a) Yu Z-T, Liao Z - L, Jiang Y -S, Li G - H and Chen J -S 2005 Chem. Eur. J. 11 2642; (b) Mahata P,
Sankar G, Madras G and Natarajan S 2005 Chem. Commun. 5787

63. Fujita M, Kwon Y J, Washizu S and Ogura K 1994 J. Am. Chem. Soc. 1161151

64. Neogi S, Sharma M K and Bharadwaj P K 2009 J. Mol. Catal. A. 2991

65. Llabres i Xamena F X, Abad A, Corma A and Garcia H 2007 J. Catal. 250294

66. Shultz A M, Farha O K, Hupp J T and Nguyen S T 2009 J. Am. Chem. Soc. 1314204

67. Maspoch D, Ruiz-Molina D, Wurst K, Domingo N, Cavallini M, Biscarini F, Tejada J, Rovira C and Veciana J 2003 Nat. Mater. 2190

68. Mahata P, Sarma D and Natarajan S 2010 J. Chem. Sci. 12219

69. Mahata P, Natarajan S, Panissod P and Drillon M 2009 J. Am. Chem. Soc. 13110140

70. (a) Mahata P, Sen D and Natarajan S 2008 Chem. Commun. 1278; (b) Mahata P, Sundaresan A and Natarajan S 2007 Chem. Commun. 4471

71. Mahata P, Ramya K V and Natarajan S 2008 Chem. Eur. J. 145839

72. Mahata P, Sarma D, Madhu C, Sundaresan A and Natarajan S 2011 Dalton Trans. 401952 